\title{
Structural and Thermodynamic Signatures of Ligand Binding to the Enigmatic Chitinase D of Serratia proteamaculans
}

Jogi Madhuprakash, ${ }^{\text {a,b }}$ Bjørn Dalhus, ${ }^{\mathrm{c}, \mathrm{d}}$ Gustav Vaaje-Kolstad, ${ }^{\mathrm{a}}$ Shohei Sakuda, ${ }^{\mathrm{e}}$ Appa Rao Podile, ${ }^{\mathrm{b}}$ Vincent G.H. Eijsink, ${ }^{\mathrm{a}}$ and Morten Sørlie*a

aDepartment of Chemistry, Biotechnology and Food Science, NMBU - Norwegian University of Life Sciences, P.O. Box 5003, N-1432 Ås, Norway.

${ }^{b}$ Department of Plant Sciences, School of Life Sciences, University of Hyderabad, Gachibowli, Hyderabad, India.

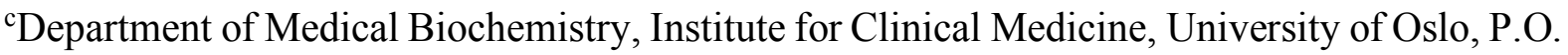
Box 4950, Nydalen, N-0424 Oslo, Norway.

dDepartment of Microbiology, Clinic for Laboratory Medicine, Oslo University Hospital, Rikshospitalet, P.O. Box 4950, Nydalen, N-0424 Oslo, Norway.

'Department of Applied Biological Chemistry, University of Tokyo, Bunkyo-Ku, Tokyo 113, Japan.

*Corresponding author: Tel: +47 64965902; fax: +47 64965901; e-mail: morten.sorlie@,nmbu.no 


\section{ABSTRACT}

The Gram-negative bacteria Serratia marcescens and Serratia proteamaculans have efficient chitinolytic machineries that degrade chitin into $N$-acetylglucosamine (GlcNAc), which is used as carbon and energy source. The enzymatic degradation of chitin in these bacteria occur through the synergistic action of glycoside hydrolases (GHs) that have complementary activities; an endo-acting $\mathrm{GH}(\mathrm{ChiC})$ making random scissions on the polysaccharide chains and two exo-acting GHs mainly target single reducing (ChiA) and non-reducing (ChiB) chain ends. Both bacteria produce low amounts of a fourth GH18 (ChiD) with an unclear role in chitin degradation. Here, we have determined the thermodynamic signatures for binding of (GlcNAc) ${ }_{6}$ and the inhibitor allosamidin to $S p C h i D$ as well as the crystal structure of $S p C h i D$ in complex with allosamidin. The binding free energies for the two ligands are $\operatorname{similar}\left(\Delta G_{\mathrm{r}}{ }^{\circ}=\right.$ $-8.9 \pm 0.1$ and $-8.4 \pm 0.1 \mathrm{kcal} / \mathrm{mol}$, respectively) with clear enthalpic penalties $\left(\Delta H_{\mathrm{r}}{ }^{\circ}=3.2 \pm\right.$ 0.1 and $1.8 \pm 0.1 \mathrm{kcal} / \mathrm{mol}$, respectively). Binding of (GlcNAc) 6 is dominated by solvation entropy change $\left(-T \Delta S_{\text {solv }}{ }^{\circ}=-17.4 \pm 0.4 \mathrm{kcal} / \mathrm{mol}\right)$ and the conformational entropy change dominates for allosamidin binding $\left(-T \Delta S_{\text {conf }}{ }^{\circ}=-9.0 \pm 0.2 \mathrm{kcal} / \mathrm{mol}\right)$. These signatures as well as the interactions with allosamidin are very similar to those of SmChiB suggesting that both enzymes are non-reducing end specific. 


\section{INTRODUCTION}

Chitin is the second most abundant biopolymer in Nature and common as a structural component in crustaceans, arthropods, fungi, and parasitic nematodes. It is an insoluble, linear polysaccharide consisting of repeated units of $\beta-1,4-N$-acetylgucosamine (GlcNAc).

In Nature, microorganisms that are able to use chitin as a carbon and energy source usually produce multiple enzymes involved in its degradation. The Gram-negative bacteria Serratia marcescens and Serratia proteamaculans produce two exo-processive family 18 glycoside hydrolases (GHs) (ChiA and $\mathrm{ChiB}$ ) that processively convert chitin chains into dimeric products moving in opposite directions and another family $18 \mathrm{GH}$ (ChiC) that is nonprocessive and endo-acting. A family 20 chitobiase is responsible for converting oligomeric chitinase products into monomeric products. Moreover, a lytic polysaccharide monooxygenase (LPMO), belonging to auxiliary activity (AA) family 10, targets crystalline regions where it uses an activated dioxygen to cleave glycosidic bonds, thus creating new access points for exoacting GHs. The genome of $S$. marcescens encodes only one such LPMO (CBP21), while the genome of S.proteamaculans encodes three such enzymes (CBP21, CBP28 and CBP50). ${ }^{1-4}$

The $S$. marcescens GH18 chitinases have a multi-modular architecture. In addition to the catalytic domains, they also have at least one carbohydrate-binding module (CBM) each. Their catalytic domains have similar overall structures, but show conspicuous differences in their substrate-binding regions that relate to varying functionalities. ChiA and $\mathrm{ChiB}$ have deep substrate-binding clefts, in part made up of a 70-90 residue ' $\alpha+\beta$ ' insertion in the catalytic domain, whereas endo-acting $\mathrm{ChiC}$ lacs this insertion and has a much more shallow substratebinding cleft. ${ }^{5-7}$ Another prominent functionally important feature is that the deep substratebinding clefts in $\mathrm{ChiA}$ and $\mathrm{ChiB}$ are lined with aromatic residues that interact with ligands and are important for the processive abilities of these enzymes. The open substrate-binding cleft of ChiC has few aromatic amino acids. ${ }^{5,8,9}$ 
Interestingly, both $S$. marcescens and S. proteamaculans possess an additional fourth potential GH18 chitinase (ChiD), which consists of a catalytic domain only. Like ChiA and $\mathrm{ChiB}, \mathrm{ChiD}$ has the ' $\alpha+\beta$ ' insertion that contributes to creating a deep substrate-binding cleft. ChiD is remarkable in displaying a high degree of innate transglycosylation (TG) and chitobiase activity in addition to hydrolytic activity towards chitin and soluble chitooligosaccarides. ${ }^{10-14}$ It has been suggested that the relatively high chitobiase activity of $S p C h i D$ is due to a loop (Asn30-Asp42) that, uniquely for ChiD, occludes the -3 and -2 subsites. $^{11}$ $\mathrm{Sm}$ ChiD is only produced in low amounts during growth on chitin, and it does not contribute significantly to degradation of chitin when present in an enzyme cocktail. Moreover, the chitobiase activity of $\mathrm{SmChiD}$ is considerably lower than the activity of the GH20 chitobiase. ${ }^{10}$ Hence, the role of this enigmatic enzyme in chitin degradation remains uncertain.

Previously, we have shown that the functional differences between $S m \mathrm{ChiA}$, SmChiB, and $\mathrm{SmChiC}$ in chitin degradation, i.e. variation in the degree and direction of processivity, are reflected in the thermodynamic signatures of substrate and inhibitor binding ${ }^{15-20}$ Since there now are known correlations between the thermodynamics of ligand binding and chitinase functionality, we have determined the thermodynamic signatures of substrate and inhibitor binding to $\mathrm{SpChiD}$ in order to learn more about the potential function of this enigmatic enzyme. In addition, we have determined the crystal structure of $S p C h i D$ bound to the well-known GH18 inhibitor allosamidin, which, notably, is expected to bind to the -3 to -1 subsites, which are thought to be occluded in $S p C h i D$. The obtained results are compared to available data for the well-characterized $S m$ ChiA, $S m \mathrm{ChiB}$, and $S m$ ChiC.

\section{EXPERIMENTAL SECTION}

Proteins and Chemicals. Allosamidin was isolated from Streptomyces $s p$. and the

purity was controlled by ${ }^{1} \mathrm{H}$ NMR as described elsewhere. ${ }^{21}$ Previously, the structure of 
allosamidin has been verified by both NMR and crystallography. ${ }^{22}$ (GlcNAc) 6 was purchased from Sigma-Aldrich (St. Louis, MO, U.S.A.). The plasmid pET-22b (+) and Escherichia coli BL21 (DE3) (Novagen, Madison, USA) were used for heterologous expression. E. coli was grown in $\mathrm{LB}$ broth $(1 \%$ peptone, $0.5 \%$ yeast extract, $1 \% \mathrm{NaCl})$ at $37^{\circ} \mathrm{C}$. Ampicillin at 100 $\mu \mathrm{g} / \mathrm{mL}$ working concentration was added to the LB broth as required. Oligonucleotide primers were purchased from Eurofins India (Bangalore, India). Restriction enzymes, T4 DNA ligase and Pfu DNA polymerase were obtained from MBI Fermentas (Ontario, Canada). Isopropyl$\beta$-D-thiogalactoside (IPTG), ampicillin and all other chemicals were purchased from Calbiochem or Merck (Darmstadt, Germany), or Hi-media labs (Mumbai, India). Ni-NTA His resin for protein purification was procured from Novagen (Madison, USA).

Generation of SpChiD-E153A. Wild-type pET-22(b)-SpChiD was used as template for generating the mutant E153A. ${ }^{23}$ Mutagenesis was performed using the QuikChange II sitedirected mutagenesis kit (Agilent Technologies), as described by the manufacturer. The primer sequences used for site-directed mutagenesis were forward: 5'-CATCGATCTCGACTGGGCTTACCCGGTTAACGGTG-3' and reverse: 5'-CACCGTTAACCGGGTA $\boldsymbol{A} \boldsymbol{G C C C A G T C G A G A T C G A T G - 3 ' . ~ T h e ~ g e n e ~ s e q u e n c e ~ a f t e r ~}$ mutagenesis was confirmed by automated DNA sequencing and the plasmid with the desired mutation was transformed into E. coli BL21 (DE3) for protein over expression.

Protein expression, isolation and Ni-NTA purification. E. coli BL21 (DE3) cells expressing wild-type $S p C h i D$ and its mutant E153A were produced as previously reported. ${ }^{12}$ Periplasmic fractions were made as described in the expression system manual of the pET (Novagen) with slight changes. Firstly, the cells were concentrated by centrifugation of a 500 $\mathrm{mL}$ culture. There were subsequently resuspended in $15 \mathrm{~mL}$ of ice-cold spheroplast buffer followed by incubation at $4{ }^{\circ} \mathrm{C}$ under mild mixing $(15 \mathrm{~min})$. The spheroplast buffer was prepared by mixing $10 \mathrm{~mL}$ of $1 \mathrm{M}$ Tris- $\mathrm{HCl}, \mathrm{pH} 8.0,20 \mathrm{~g}$ sucrose, $200 \mu \mathrm{L} 0.25 \mathrm{M}$ EDTA, $\mathrm{pH}$ 
8.0, $200 \mu \mathrm{L} 50 \mathrm{mM}$ phenylmethylsulfonyl fluoride, and distilled water to a final volume of 100 $\mathrm{mL}$. After collection of the cells by centrifugation at $7741 \mathrm{~g}$, for $8 \mathrm{~min}$ at $4{ }^{\circ} \mathrm{C}$, the pellet was resuspended in $15 \mathrm{~mL}$ of ice-cold filter-sterilized $5 \mathrm{mM} \mathrm{MgSO}_{4}$ solution and incubated at $4{ }^{\circ} \mathrm{C}$ for $10 \mathrm{~min}$, followed by centrifugation at $7741 \mathrm{~g}$, for $8 \mathrm{~min}$ at $4{ }^{\circ} \mathrm{C}$. The supernatant was sterilized using $0.2 \mu \mathrm{m}$ filters and used for protein purification. Prior to purification, the protein was transferred to equilibration buffer (50 $\mathrm{mM} \mathrm{NaH}_{2} \mathrm{PO}_{4}, 300 \mathrm{mM} \mathrm{NaCl}, 10 \mathrm{mM}$ imidazole), pH 8.0, using Amicon Ultra Centrifugal filters (10 kDa cutoff, Millipore, Billerica, MA). The proteins were purified using standard nickel affinity chromatography, as described previously. ${ }^{12}$

Crystallization with allosamidin. The purified wild-type $S p C h i D$ was incubated at various concentrations $(12,15$ and $18 \mathrm{mg} / \mathrm{mL})$ with $2.3 \mathrm{mM}$ allosamidin at $4{ }^{\circ} \mathrm{C}$, overnight, to ensure complete binding. These preformed complexes were used for vapour-diffusion crystallization screening in 96-well sitting drop trays, using a Mosquito crystallization robot (TTP Labtech, UK) and commercially available screens. Crystals appeared in several conditions of the JCSG-plus ${ }^{T M}$ (MD1-37) screen, and well diffracting crystals appeared by equilibrium against 0.1 M BICINE, pH 9.0 and 20\% (w/v) PEG 6000 as precipitant.

\section{Diffraction data collection, structure determination and model refinement.}

Crystals were flash frozen in liquid nitrogen after a short soak in reservoir solution supplemented with $20 \%$ ethylene glycol. X-ray diffraction data of SpChiD crystals cocrystallized with allosamidin were collected at the ID23-1 "Massif" beamline at the European Synchrotron Radiation Facility (ESRF), in Grenoble, France. Integration, scaling, and analyses of data was undertaken by the use of $\mathrm{XDS},{ }^{24}$ Aimless, ${ }^{25}$ and CCP4i. ${ }^{26}$ The crystal structure was obtained by molecular replacement utilizing the Phaser module within the PHENIX software. ${ }^{27}$ The ligand free crystal structure of ligand-free $S p C h i D(4 n z c . p d b)$ was used as a search model. ${ }^{11}$ Refinement was done using PHENIX ${ }^{27}$ and each refinement cycle was 
interspersed with rebuilding and manual adjustments using Coot. ${ }^{28}$ The asymmetric unit of the final model contains one protein chain of 395 residues, as well as one allosamidin molecule, 3 ethylene glycol molecules and 434 solvent water molecules. A few side chains have been modeled with two alternative conformations. Final atomic coordinates and structure factors have been deposited in the Protein Data Bank with accession code $6 \mathrm{hm} 1$.

Isothermal titration calorimetry experiments. ITC experiments were executed using a VP-ITC system from Microcal, Inc (Northampton, MA).$^{29}$ Prior to experiments, the solutions place in the reaction cell were degassed to avoid air bubbles that can cause disturbances in the base line. Samples for analysis consisted of $250 \mu \mathrm{M}$ of (GlcNAc) 6 and allosamidin, respectively, in the ITC-syringe and $15 \mu \mathrm{M}$ of $S p C h i D$ in the reaction cell. For all experiments, a $20 \mathrm{mM}$ potassium phosphate buffer of $\mathrm{pH} 6.0$ was used. During the experiments, $8 \mu \mathrm{L}$ of the titrant were added into the reaction cell at $180 \mathrm{~s}$ intervals. To obtain a temperature dependence of the reaction enthalpy change $\left(\Delta H_{\mathrm{r}}^{\circ}\right)$ of the reaction, this was determined $t$ of $20,25,30$, and $37^{\circ} \mathrm{C}$. The stirring speed was set to be $260 \mathrm{rpm}$. The end of the ITC experiments was achieved after 22-27 injections. A minimum of three independent titrations was undertaken for each binding reaction.

Analysis of calorimetric data. ITC data were collected by the Microcal Origin v.7.0 software associated with the VP-ITC system. ${ }^{29}$ All data were corrected for heat of dilution by subtracting the heat remaining after saturation of binding sites on the enzyme prior to further data analysis. For the fit of ITC-data, a non-linear least-squares algorithm and a single-site binding model in the Origin software was employed. The binding reaction data followed a single-site binding model. From the fits, the stoichiometry $(n)$ of the reaction, equilibrium binding association constant $\left(K_{\mathrm{a}}\right)$, and the $\Delta H_{\mathrm{r}}^{\circ}$ of the reaction were derived directly. Typically, the determined value of $n$ was between 0.9 and 1.1 for each independent reaction. The 
equilibrium binding dissociation constant $\left(K_{\mathrm{d}}\right)$, reaction free energy change $\left(\Delta G_{\mathrm{r}}^{\circ}\right)$ and the reaction entropy change $\left(\Delta S_{\mathrm{r}}^{\circ}\right)$ were then calculated from the relations depicted in Equation 1.

$$
\Delta G_{\mathrm{r}}^{\circ}=-R T \ln K_{\mathrm{a}}=R T \ln K_{\mathrm{d}}=\Delta H_{\mathrm{r}}^{\circ}-T \Delta S_{\mathrm{r}}^{\circ}
$$

Errors are reported as standard deviations of at least three experiments at each temperature. The methodology used for parameterization of the entropic term has been described in detail previously. ${ }^{16,30}$

\section{RESULTS}

Binding of (GIcNAc)6 and allosamidin to SpChiD. Since the E153Q mutant of SpChiD still showed significant catalytic activity, ${ }^{14}$ the binding free energy of (GlcNAc) 6 (Fig. 1) was determined with a mutant containing the E153A single point mutation.
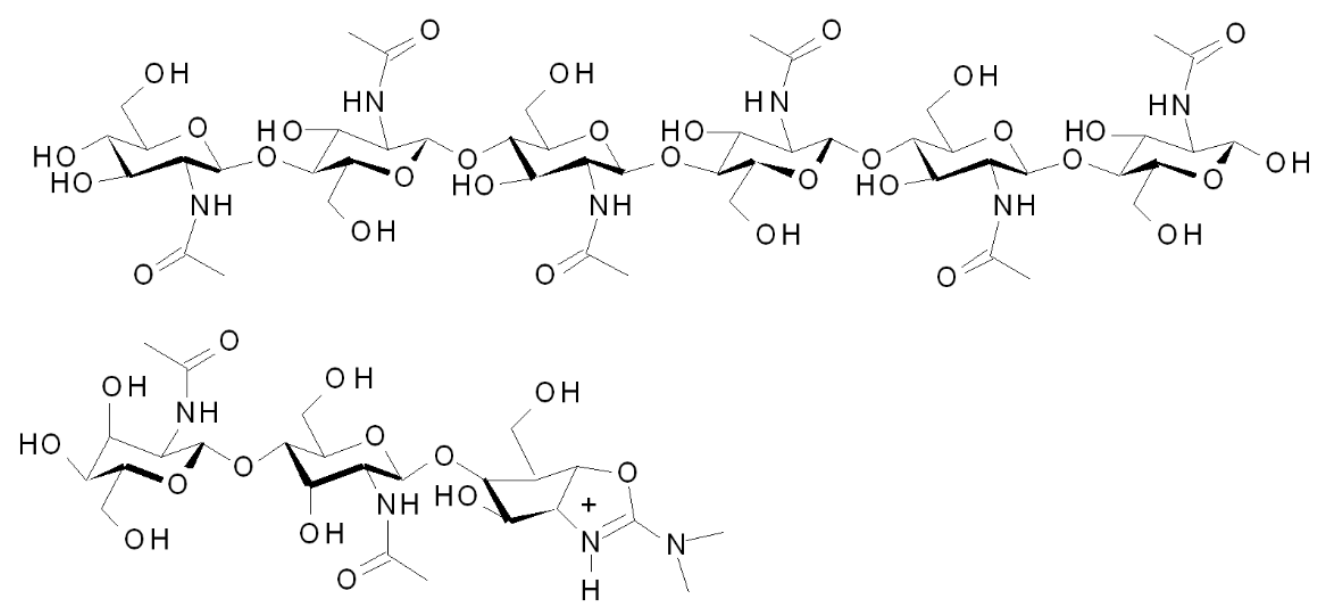

Figure 1. Molecular structures of (GlcNAc) 6 (top) and allosamidin (bottom). 
Time (min)
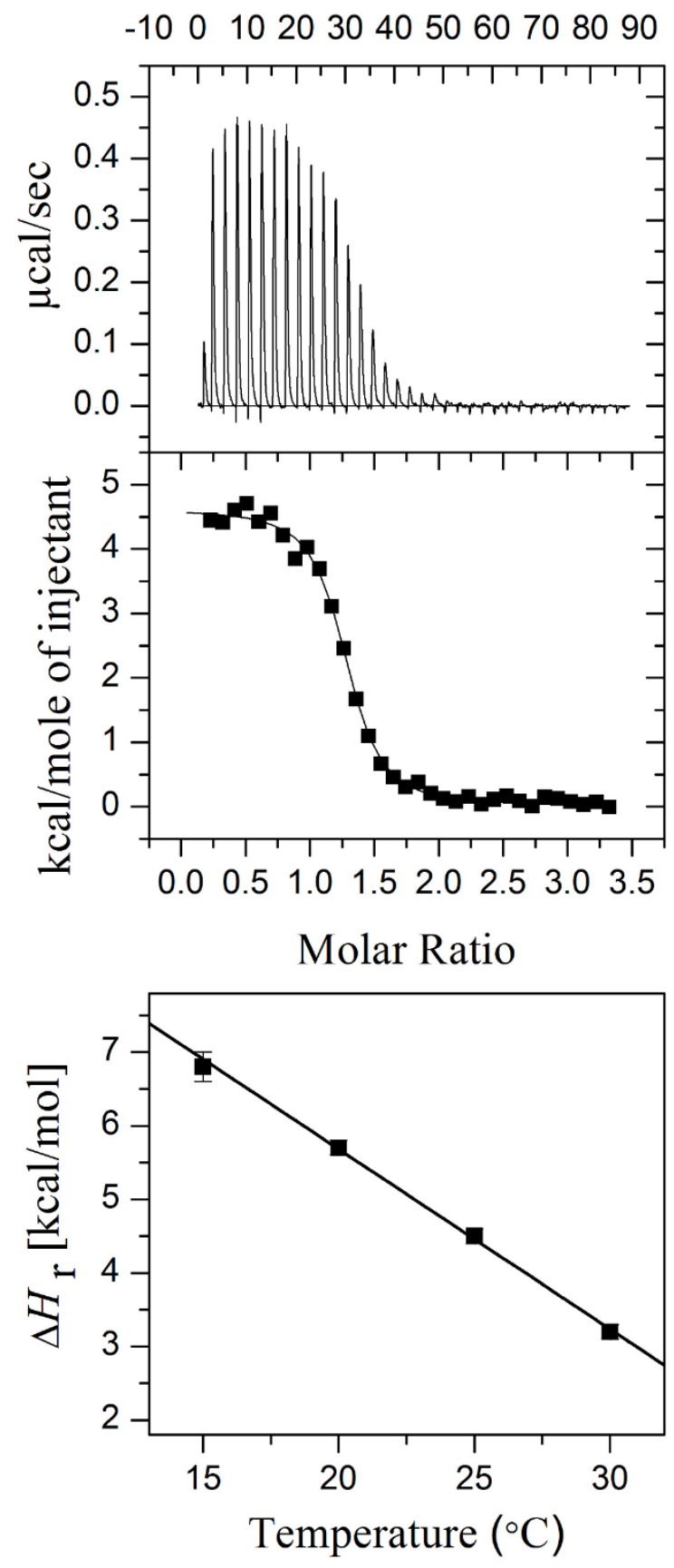

Time (min)
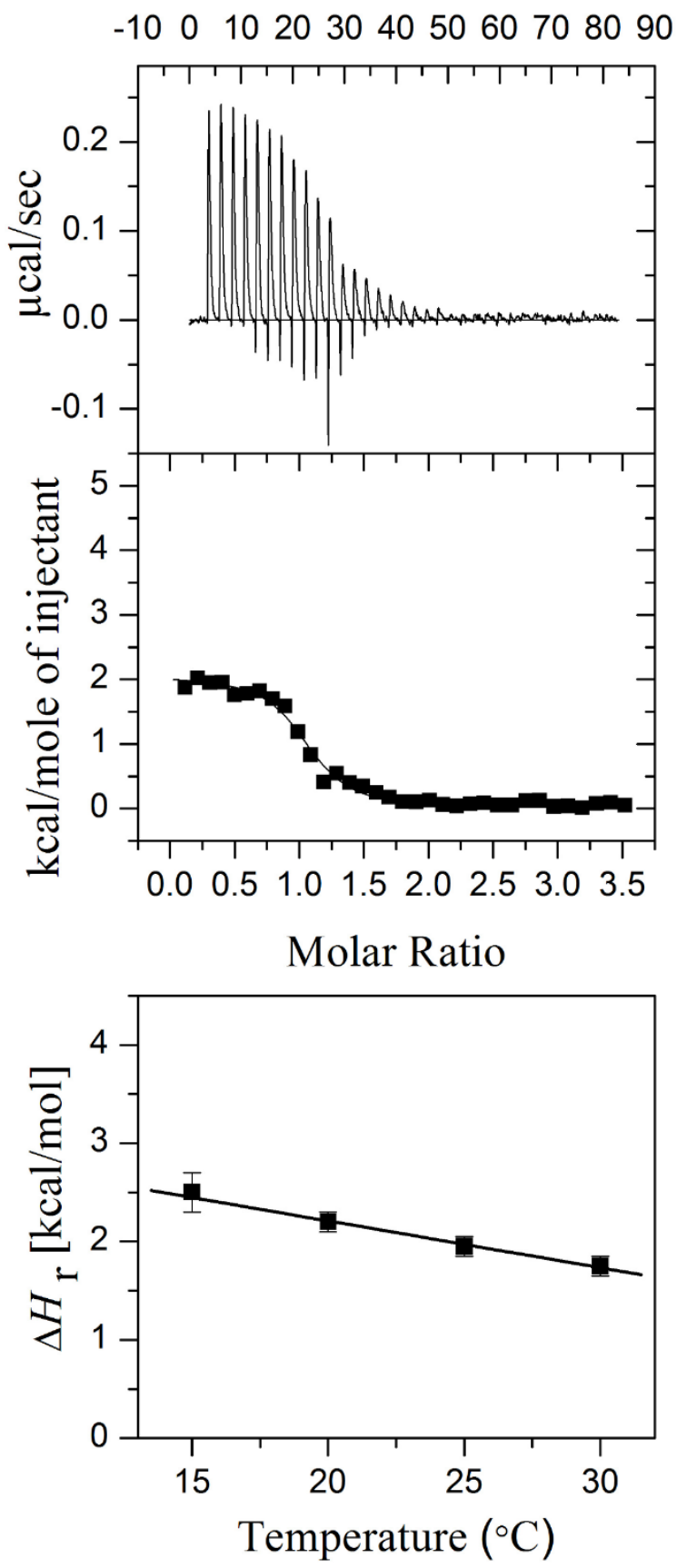

Figure 2. Thermograms (upper panel) and binding isotherms with theoretical fits (middle panel) obtained for binding of (GlcNAc) 6 (left) or allosamidin (right) to $\mathrm{SpChiD}$ at $\mathrm{pH} 6.0$ and $t=30^{\circ} \mathrm{C}$ in $20 \mathrm{mM}$ potassium phosphate. The lower panels show the temperature dependency of binding of (GlcNAc) 6 (left) and allosamidin (right) at pH 6.0. The plot of $\Delta H_{\mathrm{r}}^{\circ}$ vs. temperature yields the change in heat capacity $\left(\Delta C_{\mathrm{p}, \mathrm{r}}{ }^{\circ}\right)$ as the slope. The derived values of $\Delta C_{\mathrm{p}, \mathrm{r}}{ }^{\circ}$ are $-240 \pm 6 \mathrm{cal} / \mathrm{K} \mathrm{mol}$ and $-50 \pm 3 \mathrm{cal} / \mathrm{K}$ mol, respectively. 
Table 1. Thermodynamic parameters for ligand binding to $S m \mathrm{ChiA}, S m \mathrm{ChiB}, S m \mathrm{ChiC}$, and SpChiD at $t=30^{\circ} \mathrm{C}, \mathrm{pH}=6.0$

\begin{tabular}{|c|c|c|c|c|c|c|c|}
\hline Enzyme $K_{\mathrm{d}^{\mathrm{a}}}$ & $\Delta G_{\mathrm{r}}^{\mathrm{ob}}$ & $\Delta H_{\mathrm{r}}^{\mathrm{ob}}$ & $-T \Delta S_{\mathrm{r}}^{\mathrm{ob}}$ & $-T \Delta S_{\mathrm{solv}}^{\mathrm{ob}, \mathrm{c}}$ & $-T \Delta S_{\mathrm{conf}}^{\mathrm{ob}, \mathrm{d}}$ & $-T \Delta S_{\mathrm{mix}}{ }^{\text {ob,d }}$ & $\Delta C_{\mathrm{p}, \mathrm{r}} \mathrm{oe}, \mathrm{f}$ \\
\hline \multicolumn{8}{|c|}{$\underline{(\mathrm{GlcNAc})_{6}}$} \\
\hline $\operatorname{Sm} \mathrm{ChiA}^{\mathrm{g}} 0.56 \pm 0.03$ & $-8.7 \pm 0.1$ & $-4.5 \pm 0.2$ & $-4.2 \pm 0.2$ & $-17.5 \pm 1.0$ & $10.9 \pm 1.0$ & 2.4 & $-241 \pm 12$ \\
\hline $\operatorname{Sm} \mathrm{ChiB}^{\mathrm{h}} 0.20 \pm 0.03$ & $-9.3 \pm 0.1$ & $-0.1 \pm 0.3$ & $-9.2 \pm 0.3$ & $-11.5 \pm 0.5$ & $-0.1 \pm 0.6$ & 2.4 & $-158 \pm 5$ \\
\hline $\mathrm{SmChiC}^{\mathrm{g}} 0.10 \pm 0.02$ & $-9.7 \pm 0.1$ & $-7.8 \pm 0.2$ & $-1.9 \pm 0.2$ & $-11.5 \pm 1.0$ & $7.2 \pm 1.0$ & 2.4 & $-158 \pm 12$ \\
\hline SpChiD $\quad 0.35 \pm 0.09$ & $-8.9 \pm 0.1$ & $3.2 \pm 0.1$ & $-12.1 \pm 0.1$ & $-17.4 \pm 0.4$ & $2.9 \pm 0.4$ & 2.4 & $-240 \pm 6$ \\
\hline
\end{tabular}

\begin{tabular}{|c|c|c|c|c|c|c|c|}
\hline \multicolumn{8}{|c|}{$\underline{\text { Allosamidin }}$} \\
\hline $\operatorname{Sm}_{\text {ChiA }^{\mathrm{i}}} 0.17 \pm 0.06$ & $-9.4 \pm 0.2$ & $-6.2 \pm 0.2$ & $-3.2 \pm 0.3$ & $-4.5 \pm 1.3$ & $-1.1 \pm 1.3$ & 2.4 & $-61 \pm 13$ \\
\hline $\mathrm{SmChiB}^{\mathrm{j}} \quad 0.16 \pm 0.04$ & $-9.4 \pm 0.1$ & $3.8 \pm 0.2$ & $-13.2 \pm 0.2$ & $-4.5 \pm 0.5$ & $-11.1 \pm 0.6$ & 2.4 & $-63 \pm 4$ \\
\hline$S_{m}$ ChiC $^{\mathrm{i}} 2.0 \pm 0.2$ & $-7.9 \pm 0.1$ & $-0.6 \pm 0.1$ & $-7.3 \pm 0.1$ & $-8.7 \pm 1.3$ & $-1.0 \pm 1.3$ & 2.4 & $-120 \pm 15$ \\
\hline SpChiD $\quad 0.91 \pm 0.09$ & $-8.4 \pm 0.1$ & $1.8 \pm 0.1$ & $-10.2 \pm 0.1$ & $-3.6 \pm 0.2$ & $-9.0 \pm 0.2$ & 2.4 & $-50 \pm 3$ \\
\hline
\end{tabular}

Binding of $(\mathrm{GlcNAc})_{6}$ to $\mathrm{SpChiD}$ at $\mathrm{pH} 6.0$ (20 $\mathrm{mM}$ potassium phosphate buffer) at temperatures of $20,25,30$, and $37^{\circ} \mathrm{C}$ was investigated using ITC. In Figure 2, a representative ITC thermogram and its theoretical fit to the data obtained in the experiment is depicted at $t$ $=30{ }^{\circ} \mathrm{C}$. At this temperature, $\operatorname{SpChiD}$ binds (GlcNAc) 6 with a $K_{\mathrm{d}}$ of $=0.35 \pm 0.09 \mu \mathrm{M}\left(\Delta G_{\mathrm{r}}^{\circ}=\right.$ $-8.9 \pm 0.1 \mathrm{kcal} / \mathrm{mol}$, Table 1$)$. The reaction is accompanied by an enthalpic change $\left(\Delta H_{\mathrm{r}}^{\circ}\right)$ of $3.2 \pm 0.1 \mathrm{kcal} / \mathrm{mol}$ and an entropic change $\left(\Delta S_{\mathrm{r}}^{\circ}\right)$ of $40 \pm 1 \mathrm{cal} / \mathrm{K}$ mol, giving a $-T \Delta S_{\mathrm{r}}{ }^{\circ}$ of -12.1 $\pm 0.1 \mathrm{kcal} / \mathrm{mol}$. Using data collected at different temperatures, the change in heat capacity $\left(\Delta \mathrm{C}_{\mathrm{p}, \mathrm{r}}{ }^{\circ}\right)$ as determined by Equation 2, was determined to be $-240 \pm 6 \mathrm{cal} / \mathrm{K} \cdot \mathrm{mol}$ (Fig 2). 


$$
\Delta C_{\mathrm{p}, \mathrm{r}}^{\mathrm{o}}=\left(\frac{\partial \Delta H_{\mathrm{r}}^{\mathrm{o}}}{\partial \mathrm{T}}\right)
$$

Binding of allosamidin (Fig. 1) to $S p$ ChiD was also studied using ITC at pH $6.0(20 \mathrm{mM}$ potassium phosphate buffer) at temperatures of $20,25,30$, and $37{ }^{\circ} \mathrm{C}$. In Figure 2 , a representative ITC thermogram and its theoretical fit to the data obtained in the experiment is depicted at $t=30^{\circ} \mathrm{C}$. At this temperature, $S p C h i D$ binds allosamidin with a $K_{\mathrm{d}}$ of $=0.91 \pm 0.09$ $\mu \mathrm{M}\left(\Delta G_{\mathrm{r}}^{\circ}=-8.4 \pm 0.1 \mathrm{kcal} / \mathrm{mol}\right.$, Table 1$)$. The reaction is accompanied by an enthalpic change $\left(\Delta H_{\mathrm{r}}{ }^{\circ}\right)$ of $1.8 \pm 0.1 \mathrm{kcal} / \mathrm{mol}$ and an entropic change $\left(\Delta S_{\mathrm{r}}{ }^{\circ}\right)$ of $34 \pm 1 \mathrm{cal} / \mathrm{K} \mathrm{mol}\left(-T \Delta S_{\mathrm{r}}{ }^{\circ}=-10.2\right.$ $\pm 0.1 \mathrm{kcal} / \mathrm{mol}$ ). The change in heat capacity was determined to be $-50 \pm 3 \mathrm{cal} / \mathrm{K} \mathrm{mol}$ (Fig. 2 ; Table 1).

The allosamizoline group of allosamidin (Fig. 1) contains a 2-aminooxazoline functional group, which typically has a $\mathrm{p} K_{\mathrm{a}}$ value around 8.6. ${ }^{33}$ This means that allosamidin will have a positive charge at $\mathrm{pH} 6$ that will interact with the Asp - Glu catalytic diad in the 1 subsite. If the diad is to form a strong electrostratic - electrostatic interaction with the allosamizoline group, a proton needs to be released. ${ }^{16}$ Therefore, the $\mathrm{p} K_{\mathrm{a}}$ of the diad can be assessed by determining potential protonation/deprotonation effects coupled to allosamidin and this can be achieved by measuring the contribution from buffer ionization to $\Delta H_{\mathrm{r}}{ }^{\circ} \cdot{ }^{34}$ In addition to $20 \mathrm{mM}$ potassium buffer (ionization heat of $1.22 \mathrm{kcal} / \mathrm{mol}$ ), ITC experiments were carried out at identical buffer concentrations at pH 6.0 in PIPES (ionization heat of $2.72 \mathrm{kcal} / \mathrm{mol}$ ) and imidazole (ionization heat of $8.75 \mathrm{kcal} / \mathrm{mol}$ ). ${ }^{35} \mathrm{The} \Delta H_{\mathrm{r}}{ }^{\circ}$ values, $3.2 \pm 0.1 \mathrm{kcal} / \mathrm{mol}, 1.0 \pm 0.2$ $\mathrm{kcal} / \mathrm{mol}$ and $-2.3 \pm 0.2 \mathrm{kcal} / \mathrm{mol}$ for phosphate, PIPES and imidazole, respectively, were plotted as a function of the ionization enthalpy of the buffer and fitted to Equation $3:{ }^{34}$

$$
\Delta H_{\mathrm{r}}^{\circ}=\Delta H_{\text {ind }}^{\circ}+n \mathrm{H}^{+} \bullet \Delta H_{\text {ion }}^{\circ}
$$


In this equation, $\Delta H_{\text {ind }}{ }^{\circ}$ is the buffer-independent enthalpy change and $n \mathrm{H}^{+}$is the number of protons taken up or released by the enzyme upon ligand binding. ${ }^{34}$ The slope of the linear regression curve indicates that at 0.55 protons are transferred from the enzyme-ligand complex to the buffer $\left(n \mathrm{H}^{+}=-0.55 \pm 0.04\right.$ with $\left.\Delta H_{\text {ind }}{ }^{\circ}=2.5 \mathrm{kcal} / \mathrm{mol}\right)$ at $\mathrm{pH} 6.0$. This suggest that 55 $\%$ of the diad is in its acidic form at $\mathrm{pH} 6.0$, which implies a $\mathrm{p} K_{\mathrm{a}}$ of 6.09 , i.e. a value quite similar to values obtained for the other GH18 chitinases from S. marcescens (Table 2).

Table 2. Estimated $\mathrm{p} K_{\mathrm{a}}$ values for the catalytic diad obtained from the buffer dependency of allosamidin binding to the individual chitinases.

\begin{tabular}{|c|c|c|c|c|}
\hline & $\mathrm{SmChiA}^{\mathrm{a}}$ & $\mathrm{SmChiB}^{\mathrm{b}}$ & $\mathrm{SmChiC}^{\mathrm{a}}$ & SpChiD \\
\hline$\overline{\mathrm{p} K_{\mathrm{a}}}$ & 6.03 & 6.95 & 5.65 & 6.09 \\
\hline
\end{tabular}

Parameterization of the entropic term. The entropic term, $\Delta S_{\mathrm{r}}^{\circ}$, can be viewed as the sum of translational, solvation, and conformational entropic changes as shown in Equation $4 .{ }^{31}$

$$
\Delta S_{\mathrm{r}}^{\circ}=\Delta S_{\text {mix }}^{\circ}+\Delta S_{\text {solv }}^{\circ}+\Delta S_{\text {conf. }}^{\circ}
$$

When examining the entropic term, any entropic change $\left(\Delta S_{T}\right)$ at a given temperature can be calculated once $\Delta C_{\mathrm{p}, \mathrm{r}}{ }^{\circ}$ has been obtained and the entropy change has been determined at a reference temperature $\left(\Delta S_{T R}\right)$ because entropy changes are temperature dependent (Eq. 5):

$$
\Delta S_{T}=\Delta S_{T R}+\int_{T R}^{T} \Delta C_{\mathrm{p} . \mathrm{r}} d \ln T=\Delta S_{T R}+\Delta C_{\mathrm{p} . \mathrm{r}} \ln \left(\frac{T}{T R}\right)
$$

For solvation entropy changes, the reference temperature normally corresponds to temperatures at which hydration is zero. This temperature has been estimated to be $385 \mathrm{~K}$. There are several 
experiments that allude to this temperature. The entropy of transfer of six liquid hydrocarbons, as a model for hydrophobic interaction in protein folding, reaches zero at $385.5 \pm 2.2 \mathrm{~K}^{31}$ Also, plotting entropy changes versus heat capacity changes for denaturation of 11 proteins, apolar gases, saturated hydrocarbon gases, and solid cyclic dipeptides yield linear plots, and the temperature of $385 \mathrm{~K}$ comes from the slopes after least-squares fits of the data. ${ }^{37} \mathrm{~A}$ similar result was obtained when 8 different alcohols were investigated. ${ }^{36}$ Inserting $T R=385 \mathrm{~K}$ and $\Delta S_{T R}=0$ into Eq 5 and rearranging, the solvation entropy at any given temperature (i.e. $T=$ $298 \mathrm{~K})$ can be estimated when $\Delta C_{\mathrm{p}, \mathrm{r}}^{\circ}$ is known (Eq 6).

$$
\Delta S_{\mathrm{solv}}^{\mathrm{o}}=\Delta C_{\mathrm{p}, \mathrm{r}}^{\mathrm{o}} \ln \left(\frac{303 \mathrm{~K}}{385 \mathrm{~K}}\right)
$$

Using this relationship, the $\Delta S_{\text {solv }}^{\circ}$ for binding of (GlcNAc) 6 is $57 \pm 1 \mathrm{cal} / \mathrm{K} \mathrm{mol}$, representing $-17.4 \pm 0.4 \mathrm{kcal} / \mathrm{mol}\left(-T \Delta S^{\circ}{ }_{\text {solv }}\right)$ of the total free energy change of $-8.9 \mathrm{kcal} / \mathrm{mol}$ (Table 1$)$. Similar values for allosamidin binding are $\Delta S^{\circ}$ solv of $12 \pm 1 \mathrm{cal} / \mathrm{K}$ mol, representing $-3.6 \pm 0.2$ $\mathrm{kcal} / \mathrm{mol}\left(-T \Delta S^{\circ}\right.$ solv $)$ of the total free energy change of $-8.4 \mathrm{kcal} / \mathrm{mol}$.

The translational entropy change $\left(\Delta S^{\circ}{ }_{\text {mix }}\right)$ of the reaction can be calculated as a 'cratic' term, a statistical correction that reflects mixing of solute and solvent molecules, and effectively accounts for entropy change due to changes in translationa $V$ rotational degrees of freedom (Equation 6): ${ }^{31}$

$$
\Delta S_{\mathrm{mix}}^{\mathrm{o}}=R \ln \left(\frac{1}{55.5}\right)
$$

Using this approach, a $\Delta \mathrm{S}^{\circ}{ }_{\text {mix }}$ of $-8 \mathrm{cal} / \mathrm{K}$ mol can be calculated, corresponding to a $-T \Delta \mathrm{S}^{\circ}$ mix of $2.4 \mathrm{kcal} / \mathrm{mol}$. This then allows for the calculation of the conformational entropy change $\left(\Delta S^{\circ}{ }_{\text {conf }}\right)$ using Equation 3, resulting in values of $-10 \pm 1 \mathrm{cal} / \mathrm{K} \mathrm{mol}\left(-T \Delta S^{\circ}{ }_{\text {conf }}=2.9 \pm 0.4\right.$ 
$\mathrm{kcal} / \mathrm{mol})$ and $30 \pm 1 \mathrm{cal} / \mathrm{K} \mathrm{mol}\left(-T \Delta \mathrm{S}^{\circ}{ }_{\text {conf }}=-9.0 \pm 0.2 \mathrm{kcal} / \mathrm{mol}\right)$, for binding of $(\mathrm{GlcNAc})_{6}$ and allosamidin, respectively (Table 1).

Crystal Structure of SpChiD in complex with allosamidin. A crystal structure determination study was undertaken to compare the intermolecular interactions between allosamidin in $S p$ ChiD to those in $S m$ ChiA, $S m$ ChiB, and $S m$ ChiC. A crystal of $S p C h i D$ in complex with allosamidin was obtained by incubating the wild type with allosamidin prior to crystallization. The structure was determined at a resolution of $1.54 \AA$ (Table 3 ) and revealed the presence of the allosamidin molecule bound to subsites -3 to -1 (Figure 3). Intermolecular interactions between $\mathrm{SpChiD}$ and allosamidin are listed in Supplementary Figure 1. The overall structure of the protein was essentially identical to the four other published $S p C h i D$ structures available in the PDB (PDB ids 4LGX, 4NZC, 4PTM and 4Q22), with one major exception: In the $S p C h i D$ apo-enzyme and variants containing GlcNAc in the active site, a loop, connecting the first $\beta$-strand and $\alpha$-helix of the $(\beta / \alpha)_{8}$ barrel, hinged by two glycine residues (loop amino acid sequence: GGDVTAGPGG) occupies and blocks the -2 and -3 subsite (Fig. 3). The loop is bound to the active site mainly through water-mediated contacts and through a bifurcated hydrogen bond connecting the $\mathrm{Thr}^{36}$ hydroxyl group to the side chains of $\mathrm{Arg}^{278}$ and $\mathrm{Asp}^{323}$. In the $S p C h i D$ structure containing allosamidin, the inhibitor has displaced the loop by occupation of the -1 to -3 subsites. No electron density can be observed for the loop, indicating high flexibility. The displacement of the flexible loop and binding of allosamidin is also accompanied by changes in the side chain positions of $\mathrm{Asp}^{323}$ Tyr $^{325}$ and $\mathrm{Phe}^{58}$ (Fig. 3, panel C). Most other GH18 chitinases also have a loop of variable length connecting the first $(\beta / \alpha)_{8}$ barrel $\beta$-strand and $\alpha$-helix (regularly also containing short $\alpha$-helixes), although none of these block the non-reducing side of the active site and most are neither hinged by glycine residues. On the other hand, GH18 chitinases containing a similar flexible loop are found in a large variety of species in the Enterobacteriaceae family. ${ }^{13}$ 


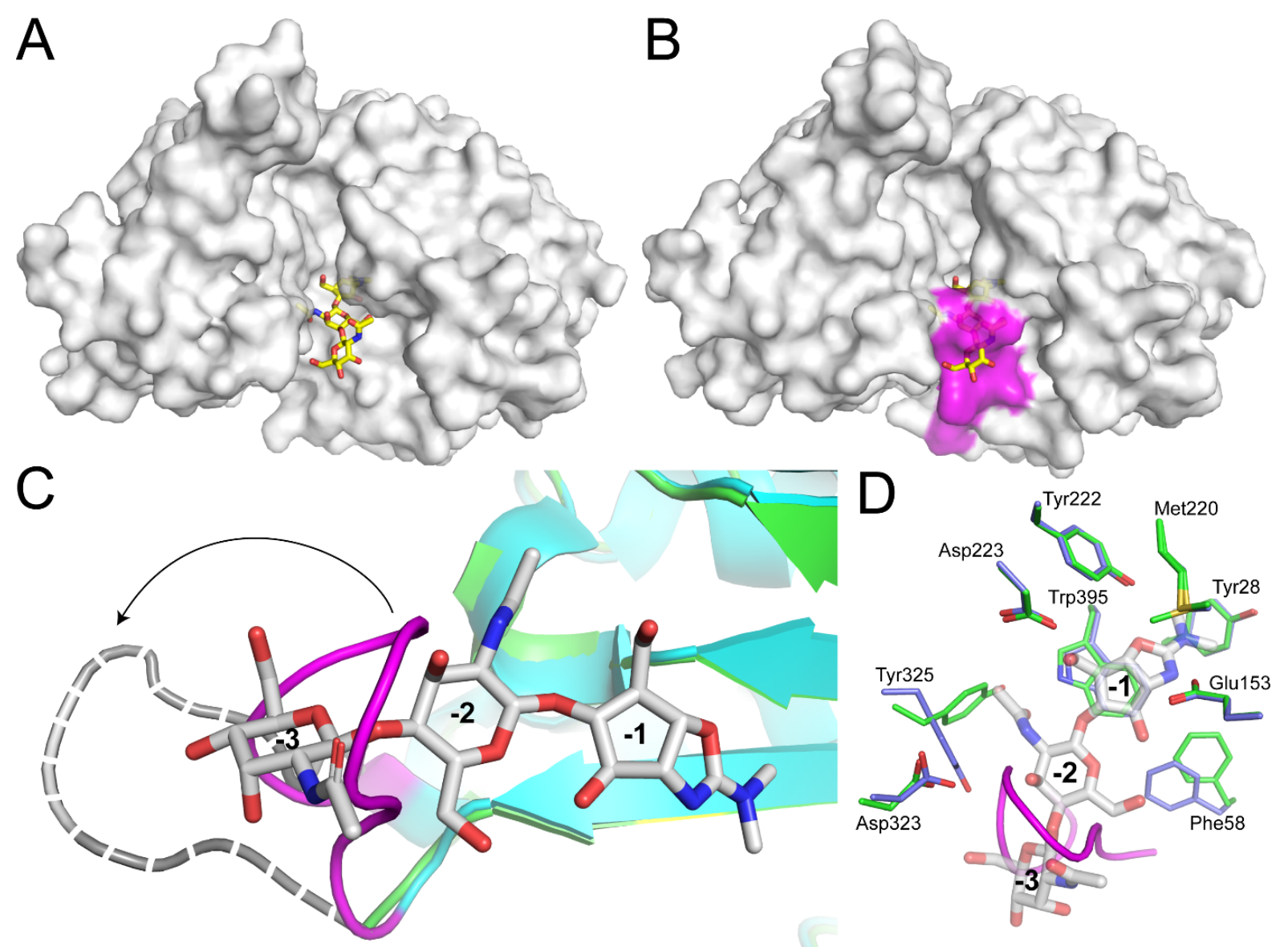

Figure 3. Allosamidin binds to the -3 to -1 subsites of $S p C h i D(A)$ displacing a flexible loop (colored in pink surface representation) that occludes the -3 and -2 subsites in the apoenzyme (B). The position of allosamidin observed in the $S p$ ChiD-allosamidin complex is also shown in the apo-enzyme structure displayed in panel B. It should be noted that the flexible loop is not observed in the allosamidin-SpChiD complex structure due to disorder. The putative movement of the loop upon binding of allosamidin is indicated in panel $\mathrm{C}$ by an arrow. The new position of the loop is shown by a dashed grey loop structure, which was drawn by hand in order to aid interpretation of the loop movement. The details of allosamidin binding, illustrated by a superpositioning of the $S p C h i D$ apo-enzyme (side chains shown in blue colored carbon atoms) and allosamidin-complex (side chains shown in green colored carbon atoms) is shown in panel D. Allosamidin is shown in grey colored carbon atoms and the flexible loop of the apo-enzyme is shown in pink cartoon. Some active site residues are not shown for clarity. Subsites are indicated by numers. 
Table 3. Crystal data, data-collection statistics and refinement data.

\section{Data Collection}

Beamline

ID23-1 (ESRF, Grenoble)

Wavelength $(\AA)$

0.97319

Temperature $(\mathrm{K})$

100

Space Group

$P 2{ }_{1} 2_{1} 2_{1}$

Unit-cell parameters $\left(\AA,{ }^{\circ}\right)$

$a=60.777, b=62.855, c=103.183$

Resolution $(\AA)$

$43.69-1.54(1.60-1.54)^{\mathrm{a}}$

Unique reflections

$57471(5508)$

Completeness (\%)

$96.9(96.2)$

Multiplicity

Mean I/ $\sigma \mathrm{I}$

$12.5(1.8)$

$\mathrm{R}_{\text {merge }}\left(\right.$ all I $\mathrm{I}^{+}$and $\mathrm{I}^{-}$)

$0.054(0.603)$

\section{Refinement statistics}

Resolution of data used in $43.69-1.54$

refinement

Completeness for range (\%) 97.0

$\mathrm{R}_{\text {cryst }} / \mathrm{R}_{\text {free }}(\%)^{\mathrm{b}}$

$16.9 / 20.3$

R.m.s.d. bonds $(\AA)$

0.005

R.m.s.d. angles $\left(^{\circ}\right)$

0.83

Average B-factor

(protein/solvent/NAG ligand) $20.7 / 30.1 / 17.2$

$\left(\AA^{2}\right)$

Number of atoms in model

Protein

Solvent waters

Allosamidin

43

Ethylene glycol

Ramachandran plot (\%) ${ }^{\mathrm{c}}$

Favorable region

Additionally allowed 2.6

${ }^{a}$ Values in parentheses are for the highest resolution shells

${ }^{\mathrm{b}} R_{\text {cryst }}=\Sigma_{\mathrm{hkl}}\left|F_{\mathrm{o}}-F_{\mathrm{c}}\right| / \Sigma_{\mathrm{hkl}}\left|F_{\mathrm{o}}\right|$ where $F_{\mathrm{o}}$ and $F_{\mathrm{c}}$ are the observed and calculated structure factor amplitudes, respectively. $R$ free is calculated from a randomly chosen $5.1 \%$ set of unique reflections not used in refinement.

${ }^{\mathrm{c}}$ Defined using MolProbity. ${ }^{37}$ 


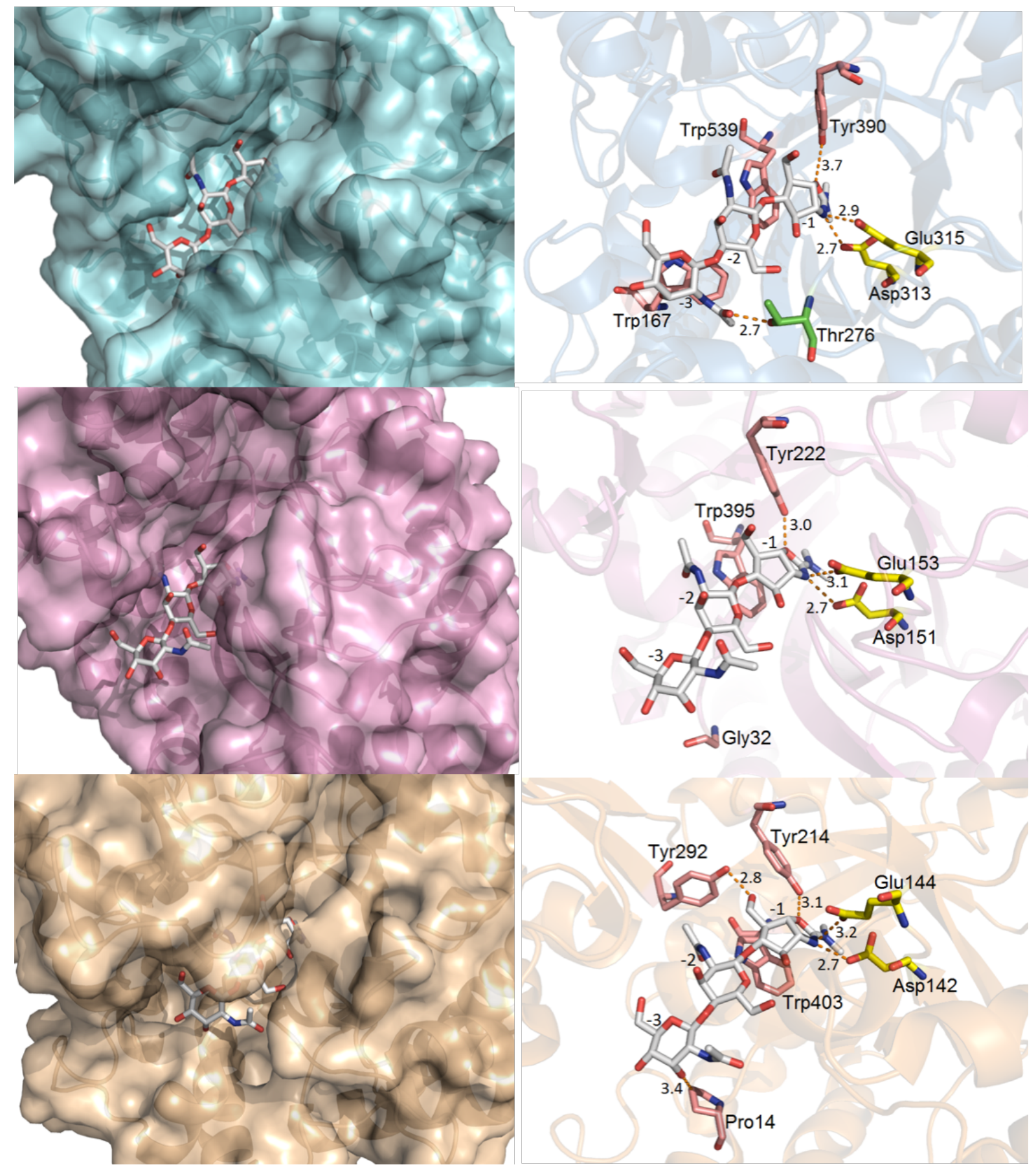

Figure 4. Aligned crystal structures of allosamidin bound to the active site of SmChiA (top) (pdb code $1 \mathrm{ffq},{ }^{38}$ ), SpChiD (middle) (pdb code $6 \mathrm{hm} 1$ ), and $S m \mathrm{ChiB}$ (bottom) (pdb code 1e6r). ${ }^{39}$ The left panels show the active site topologies for the three GH18s. A "roof" is formed in $S m$ ChiB upon ligand binding while the flexible loop has been displaced in SpChiD. The right panels show interacting side chains, which are labelled, discussed in the text. Interactions involving the protein backbone interactions are omitted for clarity. 
The interactions between the three chitinases with deep catalytic clefts, $S p C h i D, S m C h i A$, and Sm ChiB and the allosamizoline moiety in the -1 subsite are very similar, including a stacking interaction with a fully conserved Trp residue in the -1 subsite $(395,539$, and 403, respectively), hydrogen bonding to the catalytic Asp-Glu diad (151-153, 313-315, and 142144), and hydrogen bonds to the backbone of a Trp residue in the +1 subsite $(114,275$, and 97), and a the side-chain of Tyr residue (222, 390, and 214) (Fig. 4). The major difference between the chitinases is observed for the interactions in the -3 subsite. Here, $S m$ ChiA has a stacking interaction with a Trp residue (167) and a strong hydrogen bond interaction with a Thr residue (276) ${ }^{15,19,39}$. These interactions are lacking in SpChiD and SmChiB. There are also differences between $S p C h i D$ and $S m C h i B$. The substrate-binding cleft of $S m C h i B$ has a bit of a tunnel-structure and a small "roof" that covers allosamidin. Moreover, there are hydrophobic contacts between $\mathrm{SmChiB}$ and allosamidin that seem stronger (shorter distances) compared to what is observed in $S p C h i D$ (see Pro ${ }^{14}$ in $S m C h i B$ vs. Gly ${ }^{32}$ in $S p C h i D ;$ Fig. 4).

\section{DISCUSSION}

The mode of action of polymer-degrading GHs, which may vary in terms of endo- vs. exoactivity, processive vs. nonprocessive action, and reducing end vs. non-reducing end binding, are governed by active site topology and dynamics. These active-site adaptations are reflected in thermodynamic features of the binding of substrates and inhibitors. Of the four Serratia chitinases mentioned above, three, $S m \mathrm{ChiA}, \mathrm{SmChiB}$, and $S p \mathrm{ChiD}$, have similar overall active site topologies (Fig. 4) and these are discussed and compared in detail below.

Because of the difference in the directionality of processive action, allosamidin binds in the so-called substrate binding sites in SmChiA, whereas these same sites are product binding sites in SmChiB. In SmChiA, these subsites, including the -3 subsite containing ChiAspecific $\operatorname{Trp}^{167}$ and $\operatorname{Thr}^{276,9}$ bind to the polymeric part of the chitin molecule that is being 
processively degraded $^{9,40,41}$, whereas the polymer binds to + subsites in $\mathrm{SmChiB}$, interacting with residues such as $\operatorname{Trp}^{97}(+1), \operatorname{Trp}^{220}(+2)$, and $\operatorname{Phe}^{190}(+3)$. $\operatorname{Trp}^{167}$ and $\operatorname{Thr}^{276}$ contribute with a binding enthalpy of 4 and $3 \mathrm{kcal} / \mathrm{mol}$, respectively, ${ }^{15,19}$ and removal of these binding interactions reduces the processive ability of the enzyme. ${ }^{9,}{ }^{42}, 43$ In $S m \mathrm{ChiB}$, the aromatic residues contributes binding enthalpies between 1 to $3.5 \mathrm{kcal} / \mathrm{mol}$ and their removal also reduces the processive ability of the enzyme. ${ }^{8,20,44,45}$ There are no indications that $S p C h i D$ acts processively. ${ }^{10}$ Its substrate binding cleft resembles that of $\mathrm{SmChiB}$ in that there are potentially strong stacking interactions in the + subsites through $\operatorname{Trp}^{114}(+1), \operatorname{Tyr}^{226}(+2)$, and $\operatorname{Trp}^{160}(+3)$, whereas there seems to be little affinity in the -2 and -3 subsites. Accordingly, it has been shown that $S p C h i D$ binds (GlcNAc $)_{4}$ from -1 to $+3(60 \%)$ and -2 to $+2(40 \%)$ clearly showing stronger enzyme - sugar interactions in positive subsites compared to negative subsites. ${ }^{12}$ Here $S p$ ChiD deviates from $S m$ ChiA and $S m$ ChiB, which both almost exclusively bind (GlcNAc) 4 from -2 to $+2 .^{46}$

Despite these differences, all three chitinases bind allosamidin with high affinity (Table 1), which is likely due to the dominating role of the many conserved interactions between the allosamizoline moiety conserved residues in the -1 subsite. The allosamizoline moiety is analogous to the -1 sugar in an intermediate state during hydrolysis ${ }^{22,47}$. Strong binding interactions in the -1 subsites are needed to achieve the energetically demanding distortion of the ${ }^{4} \mathrm{C}_{1}$-conformation of the -1 sugar moiety to the ${ }^{1,4} \mathrm{~B}$-conformation, which is required to allow for a nucleophilic attack of a water molecule at the $\mathrm{C} 1$ carbon. ${ }^{48,}{ }^{49} \mathrm{SpChiD}$ lacks obviously strong interactions with the ligand in its -2 and -3 subsites and binds allosamidin somewhat more weakly compared to $S m$ ChiA, with its strong interaction in the -3 subsite involving $\operatorname{Trp}^{167}$ and $\mathrm{Thr}^{276}$, and $\operatorname{SmChiB}$, which lacks an analogue of $\operatorname{Trp}^{167}$ but which to some extent secludes bound allosamidin from solution because of "roof" formation (Fig. 4). 
While binding of allosamidin to $S p C h i D$ is $1 \mathrm{kcal} / \mathrm{mol}$ weaker compared to $S m \mathrm{ChiA}$ and $S m \mathrm{ChiB}$, binding of the longer (GlcNAc) 6 is very similar for all three enzymes, probably reflecting the fact that in this case both substrate- and product-binding subsites are involved for all three enzymes.

The high affinity of $S p C h i D$ for ligands covering subsites -2 and -3 is somewhat remarkable since structural studies have indicated that these subsites are occluded by a loop that is hinged by glycine in $\mathrm{SpChiD}$. Indeed, the binding of allosamidin to SpChiD displaces this flexible loop and alters the conformation of three amino acids in order to accommodate ligand binding (Fig. 3). The function of the loop has previously been indicated to be important for the chitobiase activity of SpChiD. It was shown from the very recent crystallization studies that the binding of (GlcNAc) $)_{2}$ at the active site of $S p C h i D$ does not alter the conformation of loop. ${ }^{14}$ Furthermore, the residues $\mathrm{Val}^{35}$ and $\mathrm{Thr}^{36}$ from the loop region mediate favorable contacts with the incoming sugar residue, in a way that helps the correct positioning of (GlcNAc $)_{2}$ at the active site. ${ }^{11}$ Mutation of these residues or deletion of the entire loop renders the enzyme unable to hydrolyze (GlcNAc) $2 .{ }^{13}$ These studies clearly indicate that the loop flexibility and/or conformational dynamics are important for the enzyme to accommodate oligomers of chain length greater than (GlcNAc)2.

The thermodynamic signatures of ligand binding differ between the chitinases. Firstly, binding of both (GlcNAc) 6 and allosamidin is significantly less enthalpically favorable for $S p C h i D$ and $S m$ ChiB compared to what is observed for $S m$ ChiA. The $\Delta H_{\mathrm{r}}{ }^{\circ}$ is 7.7 and 8.0 $\mathrm{kcal} / \mathrm{mol}$ less favorable for (GlcNAc) 6 and allosamidin binding, respectively, to $S p C h i D$ compared to $\mathrm{SmChiA}$ (for $\mathrm{SmChiB}$, binding is 4.4 and $10 \mathrm{kcal} / \mathrm{mol}$ less favorable, respectively). This is likely due in part to the strong interaction in the -3 subsite of ChiA, which, according to previous studies can be worth as much as $4 \mathrm{kcal} / \mathrm{mol} .^{15,50}$ 
Secondly, the changes in heat capacity show that the desolvation entropy effect upon (GlcNAc) 6 binding is $6 \mathrm{kcal} / \mathrm{mol}$ more favorable for $S p C h i D$ and $S m$ ChiA compared to $S m \mathrm{ChiB}$. This is in accordance with $S p \mathrm{ChiD}$ and $S m$ ChiA having a more open cleft topology, which implies that more water molecules interact with the substrate-binding clefts and will be displaced upon substrate binding. In support of this, molecular dynamics simulations have shown that the average number of water molecules displaced by (GlcNAc) ${ }_{6}$ binding is higher for $S m$ ChiA compared to $S m \mathrm{ChiB}^{17}$. The differences in $\Delta \mathrm{C}_{\mathrm{p}, \mathrm{r}}{ }^{\circ}$ and $-T \Delta S_{\text {solv }}{ }^{\circ}$ are much smaller for allosamidin binding, which suggest that the differences seen for (GlcNAc) 6 binding are primarily due to the positive subsites at $\mathrm{pH}$ 6.0. It is important to note that favorable changes in solvation entropy may also be caused by entropically constrained water molecules and is not necessarily a measure of the number of released water molecules. In this respect, solventexposed aromatic residues that interact with substrates could be important although there is no obvious correlation because of the occurrence of such residues in the positive subsites of the chitinases and the observed variation in $-T \Delta S_{\text {solv }}{ }^{\circ}$. Furthermore, the buffer dependency of allosamdin binding demonstrate that the catalytic diad of $S m \mathrm{ChiA}, S m \mathrm{ChiB}$, and $S p C h i D$ is deprotonated upon allosamidin binding at $\mathrm{pH}$ 6.0. Previous studies have demonstrated that $K_{\mathrm{d}}$, and hence $\Delta G_{\mathrm{r}}^{\circ}$, decreases with increasing $\mathrm{pH}$ for allosamidin binding to $S m \mathrm{ChiB}$ and SmChiA. ${ }^{15,16}$ The decrease in $\Delta G_{\mathrm{r}}{ }^{\circ}$ was accompanied with a decrease in $\Delta H_{\mathrm{r}}{ }^{\circ}$. This was interpreted as there being a free energy penalty for the deprotonation of the catalytic diad, which is gradually reduced as the degree of the protonation of this diad is reduced with increasing $\mathrm{pH}$. Moreover, it was also observed that $\Delta \mathrm{C}_{\mathrm{p}, \mathrm{r}}{ }^{\circ}$ also decreased at $\mathrm{pH} 8.5$ (from -61 to $-125 \mathrm{cal} / \mathrm{K} \cdot \mathrm{mol},-T \Delta S_{\text {solv }}{ }^{\circ}=-4.5$ and $-9.5 \mathrm{kcal} / \mathrm{mol}$ ) for $S m \mathrm{ChiA}$ and (from -63 to -190 $\mathrm{cal} / \mathrm{K} \cdot \mathrm{mol},-T \Delta S_{\text {solv }}{ }^{\circ}=-4.5$ and $-13.7 \mathrm{kcal} / \mathrm{mol}$ ) for $S m \mathrm{ChiB}$. The resulting negative charge will require increased solvation, suggesting increased desolvation upon ligand binding. For (GlcNAc) ${ }_{6}$ binding, at least to $\mathrm{SmChiB}$, there is no such $\mathrm{pH}$ dependency as $\Delta \mathrm{C}_{\mathrm{p}, \mathrm{r}}{ }^{\circ}$ only changes 
from $-158 \mathrm{cal} / \mathrm{K} \cdot \mathrm{mol}\left(-T \Delta S_{\text {solv }}{ }^{\circ}=-11.5 \mathrm{kcal} / \mathrm{mol}\right)$ at $\mathrm{pH} 6.0$ to $-169 \mathrm{cal} / \mathrm{K} \cdot \mathrm{mol}\left(T \Delta S_{\text {solv }}{ }^{\circ}=\right.$ $-12.2 \mathrm{kcal} / \mathrm{mol}){ }^{32}$ This result is likely not only be due to the fact that there are no titratable groups on the ligands, but must also imply that the titratable groups remaining in the catalytic center of $S m$ ChiB after mutating the catalytic $\mathrm{Glu}^{144}$ to a non-titratable glutamine are not significantly titrated in the $\mathrm{pH}$ 6.0-8.0 range. Combined, these results show that $\Delta \mathrm{C}_{\mathrm{p}, \mathrm{r}}{ }^{\circ}$ and $\Delta S_{\text {solv }}{ }^{\circ}$ greatly depend on both the nature of ligand with respect to length and charges and the architecture of the active site.

A third interesting observation is the large difference in conformational entropy change for (GlcNAc) 6 and allosamidin binding to $S p \mathrm{ChiD}$ and $S m \mathrm{ChiB}$ compared to $S m \mathrm{ChiA}$. Binding of allosamidin to $\mathrm{SpChiD}$ and $\mathrm{SmChiB}$ is accompanied by similar, highly favorable values for $-T \Delta S_{\text {conf }^{\circ}}$ of -9.0 and $-11.1 \mathrm{kcal} / \mathrm{mol}$, respectively, in contrast to a much less favorable value for $\operatorname{SmChiA}(-1.1 \mathrm{kcal} / \mathrm{mol})$. The same trend, albeit not as favorable, is observed for $(\mathrm{GlcNAc})_{6}$ binding. Here, the approximate average difference is also in the order of $9 \mathrm{kcal} / \mathrm{mol},\left(-T \Delta S_{\text {conf }^{\circ}}\right.$ $=2.9$ and $-0.1 \mathrm{kcal} / \mathrm{mol}$ vs. $10.9 \mathrm{kcal} / \mathrm{mol}$, for $S p \mathrm{ChiD}, S m \mathrm{ChiB}$ and $S m \mathrm{ChiA}$, respctively). The less favorable $-T \Delta S_{\text {conf }^{\circ}}$ for (GlcNAc) 6 binding likely relates to the fact that long ligands are more flexible and thus lose more entropy upon binding to the enzyme. Also, larger portions of the proteins will bind (GlcNAc) 6 compared to allosamidin, resulting in a loss of flexibility in these parts of the proteins. The observed experimental difference in conformational entropy change between $S m$ ChiA and $S m \mathrm{ChiB}$ upon ligand binding is also seen in active site dynamics from molecular dynamics calculations. ${ }^{17}$ Here, the results show that $S m$ ChiA appears to rigidify upon binding (GlcNAc)6 and exhibits less fluctuation than the apo form. Similarly, the flexibility of $S m C h i B$ is virtually unchanged upon ligand binding. Moreover, it is likely that the observed displacement of the loop, which indicates increased flexibility upon ligand binding to $S p C h i D$, will also contribute favorably to the conformational entropy change. 


\section{CONCLUSIONS}

Family GH18 chitinases from S. proteamaculans and S. marcescens use the same catalytic machinery when catalyzing the hydrolysis of chitin. Still, their different and complementary functionalities, which are needed to tackle their recalcitrant substrate, require variations in active site topology, dynamics and chemical composition. The data summarized in Table 1 and the observed interactions with the intermediate analogue allosamidin as discussed above clearly show that these variations are reflected in the thermodynamics of substrate and inhibitor interactions. As discussed earlier, this is particularly applicable to reducing end vs. non-reducing end activity. The energetic penalty for "decrystallizing" a chain end, which has been calculated to be $5.6 \mathrm{kcal} / \mathrm{mol}$ per dimeric unit ${ }^{51}$, is independent of whether this is a reducing end or a non-reducing end. Still, the GH18s performing this work are endspecific, and their active sites and thermodynamic signatures of ligand binding reflect this specificity. ${ }^{9,15}$ In structural terms, the placement of aromatic amino acids along the substratebinding surface seems crucial. ${ }^{9}$ Besides the essential Trp in the -1 subsite, $S p C h i D$ and $S m C h i B$ only have aromatic amino acids in positive subsites and the thermodynamic signatures of ligand binding by these two enzymes are quite similar. Combined this suggests that $S p C h i D$ attacks chitin chains from their non-reducing end. The aromatic amino acids in the positive subsites have also shown to be essential for the observed transglycosylation activity of both $S m \mathrm{ChiB}$ and $\mathrm{SpChiD}$ due to their large hydrophobic area and substrate binding affinity. ${ }^{14,52,53}$ The crystal structure of $S p C h i D$ with allosamidin revealed the expected strong interactions with the -1 sugar moiety that undergoes the ${ }^{4} \mathrm{C}_{1}$ - to the ${ }^{1,4} \mathrm{~B}$-conformation. Interestingly, the structure also revealed that there are only one hydrogen bond interaction at the -2 and none in the -3 subsite. This, coupled with relative few, close hydrophobic interactions suggest relative weak binding affinity in these subsites, also suggested by the weaker affinity for allosamidin compared to that observed for $S m \mathrm{ChiA}$ and $\mathrm{SmChiB}$. Still, $S p$ ChiD have equal binding affinity 
for $(\mathrm{GlcNAc})_{6}$ as $\mathrm{SmChiA}$ and $\mathrm{SmChiB}$. This is in accordance with the observation that the enzyme has the unusual tendency to bind (GlcNAc) $)_{4}$ in subsites -1 to +3 and may be the active site structural determinant for the observed chitobiase activity of $\mathrm{SpChiD.}$

The present data show binding affinities and thermodynamic features of binding that place $S p C h i D$ firmly among other in-depth characterized Serratia chitinases. To some extent, this makes $S p C h i D$ even more enigmatic, since these seemingly normal ligand binding properties are accompanied by low activity on chitin and the known fact that $S p C h i D$ hardly contributes to the efficiency of chitin degradation by a cocktail of Serratia chitinases. ${ }^{10}$ The present work lays the foundation for future research to unravel the true nature of this enzyme.

ACKNOWLEDGMENTS. The authors thank the European Synchrotron Radiation Facility for beamtime (Project MX-1789) and staff at beamline ID30A-1 for assistance. This work was supported by Grants 221576, 247001, and 247730 from the Norwegian Research Council (V.G.H.E., M.S., and B.D.), by the South-Eastern Norway Regional Health Authorities, through Grant 2015095 to the Regional Core Facility for Structural Biology (B.D.), and by a DSTINSPIRE- Faculty award (IFA16-LSPA 40) (J.M.).

\section{References}

1. Purushotham, P.; Sarma, P. V. S. R. N.; Podile, A. R., Multiple chitinases of an endophytic Serratia proteamaculans 568 generate chitin oligomers. Bioresource Technol. 2012, 112, 261-269.

2. $\quad$ Suzuki, K.; Suzuki, M.; Taiyoji, M.; Nikaidou, N.; Watanabe, T., Chitin binding protein (CBP21) in the culture supernatant of Serratia marcescens 2170.

Biosci.Biotechnol.Biochem. 1998, 62, 128-135.

3. Vaaje-Kolstad, G.; Horn, S. J.; Sørlie, M.; Eijsink, V. G. H., The chitinolytic machinery of Serratia marcescens - a model system for enzymatic degradation of recalcitrant polysaccharides. FEBS J. 2013, 280, 3028-3049.

4. Vaaje-Kolstad, G.; Westereng, B.; Horn, S. J.; Liu, Z.; Zhai, H.; Sørlie, M.; Eijsink, V. G. H., An oxidative enzyme boosting the enzymatic conversion of recalcitrant polysaccharides. Science 2010, 330, 219-222. 
5. Payne, C. M.; Baban, J.; Horn, S. J.; Backe, P. H.; Arvai, A. S.; Dalhus, B.; Bjørås, M.; Eijsink, V. G. H.; Sørlie, M.; Beckham, G. T.; et al., Hallmarks of processivity in glycoside hydrolases from crystallographic and computational studies of the Serratia marcescens chitinases. J. Biol. Chem. 2012, 287, 6322-36330.

6. Perrakis, A.; Tews, I.; Dauter, Z.; Oppenheim, A. B.; Chet, I.; Wilson, K. S.; Vorgias, C. E., Crystal structure of a bacterial chitinase at 2.3 A resolution. Structure. 1994, 2, 1169 1180 .

7. van Aalten, D. M. F.; Synstad, B.; Brurberg, M. B.; Hough, E.; Riise, B. W.; Eijsink,

V. G. H.; Wierenga, R. K., Structure of a two-domain chitotriosidase from Serratia marcescens at 1.9-angstrom resolution. Proc.Natl.Acad.Sci.U.S.A 2000, 97, 5842-5847.

8. $\quad$ Horn, S. J.; Sikorski, P.; Cederkvist, J. B.; Vaaje-Kolstad, G.; Sørlie, M.; Synstad, B.; Vriend, G.; Vårum, K. M.; Eijsink, V. G. H., Costs and Benefits of Processivity in Enzymatic Degradation of Recalcitrant Polysaccharides. Proc. Natl. Acad. Sci. U.S.A. 2006, 103, 1808918094.

9. Zakariassen, H.; Aam, B. B.; Horn, S. J.; Vårum, K. M.; Sørlie, M.; Eijsink, V. G. H., Aromatic Residues in the Catalytic Center of Chitinase A from Serratia Marcescens affect Processivity, Enzyme Activity, and Biomass Converting Efficiency. J. Biol. Chem. 2009, 284, 10610-10617.

10. Tuveng, T. R.; Hagen, L. H.; Mekasha, S.; Frank, J.; Arntzen, M. O.; Vaaje-Kolstad, G.; Eijsink, V. G. H., Genomic, proteomic and biochemical analysis of the chitinolytic machinery of Serratia marcescens BJL200. Biochim. Biophys. Acta Prot. Proteom. 2017, 1865, 414-421.

11. Madhuprakash, J.; Singh, A.; Kumar, S.; Sinha, M.; Kaur, P.; Sharma, S.; Podile, A. R.; Singh, T. P., Structure of chitinase D from Serratia proteamaculans reveals the structural basis of its dual action of hydrolysis and transglycosylation. Int. J. Biochem. Mol. Biol. 2013, $4,166-178$.

12. Madhuprakash, J.; Tanneeru, K.; Purushotham, P.; Guruprasad, L.; Podile, A. R., Transglycosylation by chitinase D from serratia proteamaculans improved through altered substrate interactions. J. Biol. Chem. 2012, 287, 44619-44627.

13. Madhuprakash, J.; Bobbili, K. B.; Moerschbacher, B. M.; Singh, T. P.; Swamy, M. J.; Podile, A. R., Inverse relationship between chitobiase and transglycosylation activities of chitinase-D from Serratia proteamaculans revealed by mutational and biophysical analyses. Sci. Rep. 2015, 5, 13.

14. Madhuprakash, J.; Dalhus, B.; Rani, T. S.; Podile, A. R.; Eijsink, V. G. H.; Sørlie, M., Key residues affecting transglycosylation activity in family 18 chitinases: insights into donor and acceptor subsites. Biochemistry 2018, 57, 4325-4337.

15. Baban, J.; Fjeld, S.; Sakuda, S.; Eijsink, V. G. H.; Sørlie, M., The Roles of Three Serratia Marcescens Chitinases in Chitin Conversion are Reflected in Different Thermodynamic Signatures of Allosamidin Binding. J. Phys. Chem. B 2010, 114, 6144-6149. 16. Cederkvist, F. H.; Saua, S. F.; Karlsen, V.; Sakuda, S.; Eijsink, V. G. H.; Sørlie, M., Thermodynamic Analysis of Allosamidin Binding to a Family 18 Chitinase. Biochemistry 2007, 46, 12347-12354.

17. Hamre, A. G.; Jana, S.; Holen, M. M.; Mathiesen, G.; P., V.; Payne, C. M.; Sørlie, M., Thermodynamic relationships with processivity in Serratia marcescens family 18 chitinases. J. Phys. Chem. B 2015, 119, 9601-9613.

18. Payne, C. M.; Jiang, W.; Shirts, M. R.; Himmel, M. E.; Crowley, M. F.; Beckham, G. T., Glycoside Hydrolase Processivity is Directly Related to Oligosaccharide Binding Free Energy. J. Am. Chem. Soc. 2013, 135, 18831-18839. 
19. Hamre, A. G.; Jana, S.; Reppert, N. K.; Payne, C. M.; Sørlie, M., Processivity, Substrate Positioning, and Binding: The Role of Polar Residues in a Family 18 Glycoside Hydrolase. Biochemistry 2015, 54, 7292-7306.

20. Jana, S.; Hamre, A. G.; Wildberger, P.; Holen, M. M.; Eijsink, V. G. H.; Beckham, G. T.; Sørlie, M.; Payne, C. M., Aromatic-mediated Carbohydrate Recognition in Processive Serratia Marcescens Chitinases. J. Phys. Chem. B 2016, 120, 1236-1249.

21. Sakuda, S.; Isogai, A.; Matsumoto, S.; Suzuki, A., Search for microbial insect growth regulators. II. Allosamidin, a novel insect chitinase inhibitor. J Antibiot.(Tokyo) 1987, 40, 296-300.

22. Sakuda, S.; Isogai, A.; Matsumoto, S.; Suzuki, A.; Koseki, K., The structure of allosamidin, a novel insect chitinase inhibitor, produced by Streptomyces Sp. Tetrahedron Lett. 1986, 27, 2475-2478.

23. Madhuprakash, J.; El Gueddari, N. E.; Moerschbacher, B. M.; Podile, A. R., Production of bioactive chitosan oligosaccharides using the hypertransglycosylating chitinase-D from Serratia proteamaculans. Bioresource Technol. 2015, 198, 503-509.

24. Kabsch, W., XDS. Acta Cryst. Sec. D: Biol. Cryst. 2010, 66, 125-132.

25. Evans, P. R.; Murshudov, G. N., How good are my data and what is the resolution? Acta Cryst. Sec. D: Biol. Cryst. 2013, 69, 1204-1214.

26. Winn, M. D.; Ballard, C. C.; Cowtan, K. D.; Dodson, E. J.; Emsley, P.; Evans, P. R.; Keegan, R. M.; Krissinel, E. B.; Leslie, A. G. W.; McCoy, A.; et al., Overview of the CCP4 suite and current developments. Acta Cryst. Sec. D: Biol. Cryst. 2011, 67, 235-242.

27. Adams, P. D.; Afonine, P. V.; Bunkóczi, G.; Chen, V. B.; Echols, N.; Headd, J. J.; Hung, L.-W.; Jain, S.; Kapral, Grosse. J. et al., The Phenix software for automated determination of macromolecular structures. Methods (San Diego, Calif.) 2011, 55, 94-106. 28. Emsley, P.; Lohkamp, B.; Scott, W. G.; Cowtan, K., Features and development of Coot. Acta Cryst. Sec. D: Biol. Cryst. 2010, 66, 486-501.

29. Wiseman, T.; Williston, S.; Brandts, J. F.; Lin, L. N., Rapid Measurement of Binding Constants and Heats of Binding using a New Titration Calorimeter. Anal. Biochem. 1989, 179, 131-137.

30. Zakariassen, H.; Sørlie, M., Heat Capacity Changes in Heme Protein-Ligand Interactions. Thermochim. Acta 2007, 464, 24-28.

31. Baker, B. M.; Murphy, K. P., Dissecting the Energetics of a Protein-protein Interaction: The Binding of Ovomucoid Third Domain to Elastase. J. Mol. Biol. 1997, 268, 557-569.

32. Norberg, A. L.; Eijsink, V. G. H.; Sørlie, M., Dissecting factors that contribute to ligand-binding energetics for family 18 chitinases. Thermochim.Acta 2010, 511, 189-193.

33. Matoga, M.; Laborde-Kummer, E.; Langlois, M. H.; Dallet, P.; Bosc, J. J.; Jarry, C.; Dubost, J. P., Determination of pKa values of 2-amino-2-oxazolines by capillary electrophoresis. J.Chromatogr.A 2003, 984, 253-260.

34. Baker, B. M.; Murphy, K. P., Evaluation of linked protonation effects in protein binding reactions using isothermal titration calorimetry. Biophys. J. 1996, 71, 2049-2055. 35. Fukada, H.; Takahashi, K., Enthalpy and Heat Capacity Changes for the Proton Dissociation of Various Buffer Components in 0.1 M Potassium Chloride. Proteins 1998, 33, 159-166.

36. Murphy, K. P., Hydration and convergence temperatures - on the use and interpretation of correlation plots. Biophys. Chem. 1994, 51, 311-326.

37. Chen, V. B.; Arendall, W. B.; Headd, J. J.; Keedy, D. A.; Immormino, R. M.; Kapral, G. J.; Murray, L. W.; Richardson, J. S.; Richardson, D. C., MolProbity: all-atom structure validation for macromolecular crystallography. Acta Crystallogr.. Sec. D, Biolog.

Crystallogr. 2010, 66, 12-21. 
38. Papanikolau, Y.; Tavlas, G.; Vorgias, C. E.; Petratos, K., De novo purification scheme and crystallization conditions yield high-resolution structures of chitinase A and its complex with the inhibitor allosamidin. Acta Crystallogr. Sect. D-Biol. Crystallogr. 2003, 59, 400-403.

39. van Aalten, D. M. F.; Komander, D.; Synstad, B.; Gåseidnes, S.; Peter, M. G.; Eijsink, V. G. H., Structural insights into the catalytic mechanism of a family 18 exochitinase. Proc. Natl. Acad. Sci. U.S.A 2001, 98, 8979-8984.

40. Hult, E. L.; Katouno, F.; Uchiyama, T.; Watanabe, T.; Sugiyama, J., Molecular Directionality in Crystalline $\beta$-chitin: Hydrolysis by Chitinases A and B from Serratia Marcescens 2170. Biochem. J. 2005, 388, 851-856.

41. Igarashi, K.; Uchihashi, T.; Uchiyama, T.; Sugimoto, H.; Wada, M.; Suzuki, K.; Sakuda, S.; Ando, T.; Watanabe, T.; Samejima, M., Two-way traffic of glycoside hydrolase family 18 processive chitinases on crystalline chitin. Nat. Commun. 2014, 5.

42. Hamre, A. G.; Jana, S.; Holen, M. M.; Mathiesen, G.; Väljamäe, P.; Payne, C. M.; Sørlie, M., Thermodynamic Relationships with Processivity in Serratia marcescens Family 18 Chitinases. J. Phys. Chem. B 2015, 119, 9601-13.

43. Kurašin, M.; Kuusk, S.; Kuusk, P.; Sørlie, M.; Väljamäe, P., Slow off-rates and strong product binding are required for processivity and efficient degradation of recalcitrant chitin by family 18 chitinases. J. Biol. Chem. 2015, 290, 29074-29085.

44. Hamre, A. G.; Frøberg, E. E.; Eijsink, V. G. H.; Sørlie, M., Thermodynamics of tunnel formation upon substrate binding in a processive glycoside hydrolase. Arch. Biochem. Biophys. 2017, 620, 35-42.

45. Hamre, A. G.; Strømnes, A. G. S.; Gustavsen, D.; Vaaje-Kolstad, G.; Eijsink, V. G. H.; Sørlie, M., Treatment of recalcitrant crystalline polysaccharides with lytic polysaccharide monooxygenase relieves the need for glycoside hydrolase processivity. Carbohydr. Res. 2019, 473, 66-71.

46. Horn, S. J.; Sørlie, M.; Vaaje-Kolstad, G.; Norberg, A. L.; Synstad, B.; Vårum, K. M.; Eijsink, V. G. H., Comparative studies of chitinases A, B and C from Serratia marcescens Biocatal.Biotransfor. 2006, 24, 39-53.

47. Terwisscha van Scheltinga, A. C.; Kalk, K. H.; Beintema, J. J.; Dijkstra, B. W., Crystal-structures of hevamine, a plant defense protein with chitinase and lysozyme activity, and its complex with an inhibitor. Structure 1994, 2, 1181-1189.

48. Biarnes, X.; Ardevol, A.; Planas, A.; Rovira, C.; Laio, A.; Parrinello, M., The conformational free energy landscape of $f$-D-glucopyranose. Implications for substrate preactivation in $f$-glucoside hydrolases. J. Am. Chem. Soc. 2007, 129, 10686-10693.

49. Knapp, S.; Vocadlo, D.; Gao, Z.; Kirk, B.; Lou, J.; Withers, S. G., NAG-thiazoline, an N-Acetyl-b-hexosaminidase inhibitor that implicates acetamido participation. J. Am. Chem.

Soc. 1996, 118, 6804-6805.

50. Zolotnitsky, G.; Cogan, U.; Adir, N.; Solomon, V.; Shoham, G.; Shoham, Y., Mapping glycoside hydrolase substrate subsites by isothermal titration calorimetry. Proc.

Natl. Acad. Sci. U.S.A 2004, 101, 11275-11280.

51. Beckham, G. T.; Crowley, M. F., Examination of the $\alpha$-chitin structure and decrystallization thermodynamics at the nanoscale. J. Phys. Chem. B 2011, 115, 4516-4522.

52. Norberg, A. L.; Karlsen, V.; Hoell, I. A.; Bakke, I.; Eijsink, V. G. H.; Sørlie, M., Determination of substrate binding energies in individual subsites of a family 18 chitinase. FEBS Lett. 2010, 584, 4581-4585.

53. Zakariassen, H.; Hansen, M. C.; Jøranli, M.; Eijsink, V. G. H.; Sørlie, M., Mutational effects on transglycosylating activity of family 18 chitinases and construction of a hypertransglycosylating mutant. Biochemistry 2011, 50, 5693-5703. 
TOC

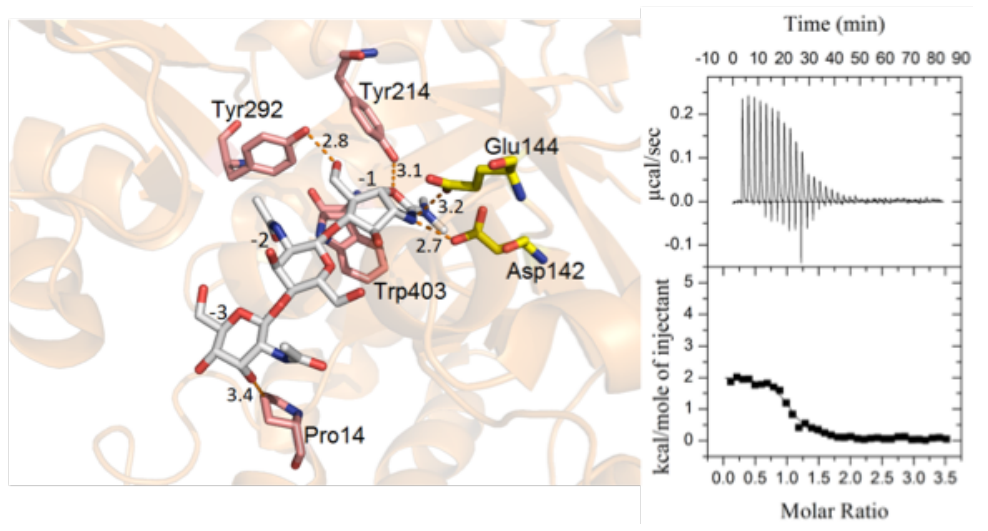

